\title{
PAROXYSMAL VENTRICULAR FIBRILLATION WITH SPONTANEOUS REVERSION TO SINUS RHYTHM*
}

\author{
BY \\ ALAN J. GOBLE \\ From the Cardiac Department, The Royal Melbourne Hospital, Victoria, Australia \\ Received April 27, 1964
}

\begin{abstract}
Ventricular fibrillation is the cause of sudden circulatory arrest in about 30 per cent of cases (Jude, Kouwenhoven, and Knickerbocker, 1961). Paroxysms of ventricular fibrillation frequently account for Stokes-Adams attacks in patients with complete heart block (Parkinson, Papp, and Evans, 1941; Portal et al., 1962). Though Stokes-Adams attacks occur not infrequently in patients with sinus rhythm, these are commonly regarded as due to ventricular asystole (Gilchrist, 1958). It is considered exceptional for spontaneous recovery of effective heart action to follow the onset of ventricular fibrillation from sinus rhythm: Zoll et al. (1956) found that defibrillation by electrical countershock was almost invariably required. Their experience has been confirmed by others, but Estes (1962) comments, "Spontaneous reversion may occur rarely, so continued massage is warranted even though no device is available for defibrillation". This approach became practicable after the introduction of external cardiac massage by Kouwenhoven, Jude, and Knickerbocker (1960).

In this paper, 2 patients are reported in whom self-limiting attacks of paroxysmal ventricular fibrillation occurred. One patient had mild hypertension and coronary artery disease; the other had severe coronary disease and massive myocardial infarction. Both patients survived. Observations were made on the manner of production, treatment, and prevention of attacks.
\end{abstract}

\section{CASE REPORTS}

Case 1. A 44-year-old electrician was known to have had hypertension for the previous 9 years, with pressures ranging between 195/130 and 140/105 mm. Hg. Throughout this period he had complained of intermittent thumping in the chest, considered due to ventricular ectopic beats. Occasionally he had sudden transient turns during which he would lose his balance. He had no chest pain. The electrocardiogram taken in January 1960 (Fig. 1) was considered to be within normal limits.

His mother died from a "heart attack" at the age of 63 , his father from "a stroke" at 58 , and one brother also from "a stroke" at the age of 45 years. One brother, aged 41, was known to have hypertension and suffered also from palpitations. Two other brothers and one sister were apparently well. Because of this family history he was apprehensive about the possibility of early death. Both he and his hypertensive brother were considered to be anxious and "worriers".

At 7.00 a.m. On June 5, 1960 he was awakened from sleep by the telephone. As he reached for the telephone he fell back unconscious. His wife thought him dead. On regaining consciousness after several minutes he was found to have wet the bed. His wife told him of the attack. It was promptly repeated. His general practitioner was called and cardiac irregularity was noted. A further attack occurred in which he was pulseless and had a minor convulsion, followed by vomiting on recovery.

When examined at 11.00 a.m., he was very apprehensive. The pulse rate was 110 a minute with frequent ventricular ectopic beats, and the arterial pressure was $160 / 100 \mathrm{~mm}$. $\mathrm{Hg}$. The electrocardiogram showed ST

* Based upon a paper presented to the Cardiac Society of Australia and New Zealand, May 31, 1963. 


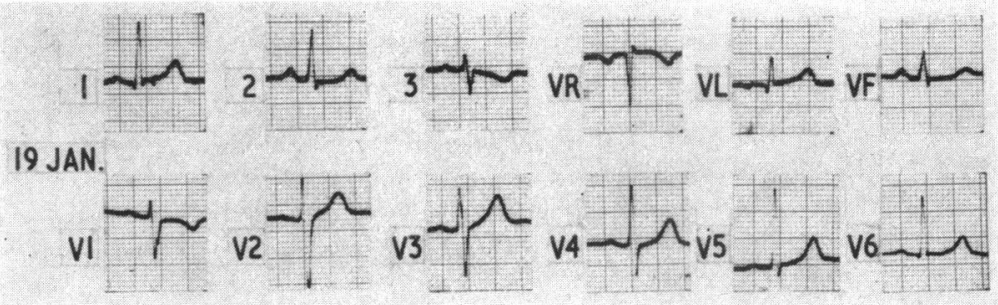

FIG. 1.-Case 1. Electrocardiogram taken in January 1960 six months before the series of StokesAdams attacks.

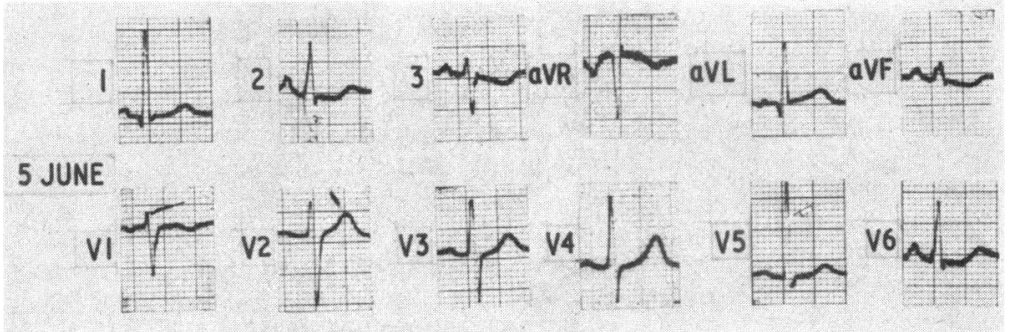

FIG. 2.-Case 1. Electrocardiogram taken on June 5, 1960 between the third and fourth StokesAdams attacks.

depression, thought to be due to myocardial ischæmia (Fig. 2). He was told he would need hospital treatment whereupon another Stokes-Adams attack occurred with unconsciousness lasting two minutes. The electrocardiogram after the attack demonstrated more frequent ectopic beats (Fig. 3). Four attacks occurred in hospital during four hours, despite the use of quinidine sulphate $800 \mathrm{mg}$. orally. He was then connected to an electrocardiograph monitor and was given procaine amide intravenously, the drip rate being adjusted to keep ectopic beats to less than one in eight normal beats, but insufficient to reduce the voltage of the QRS complex or increase its duration. He had seven further periods of unconsciousness during the next $8 \frac{1}{2}$ hours, despite a total dosage of $3.5 \mathrm{~g}$. of procaine amide. Fig. 4 shows the electrocardiographic changes during an attack. The attacks lasted from 15 seconds to 2 minutes, the last one occurring at $2.30 \mathrm{a} . \mathrm{m}$. on June 6.

It had been decided that if an attack were to last for $2 \frac{1}{2}$ minutes, thoracotomy and internal cardiac massage would be performed, followed by internal electrical defibrillation if necessary. (At that time, neither

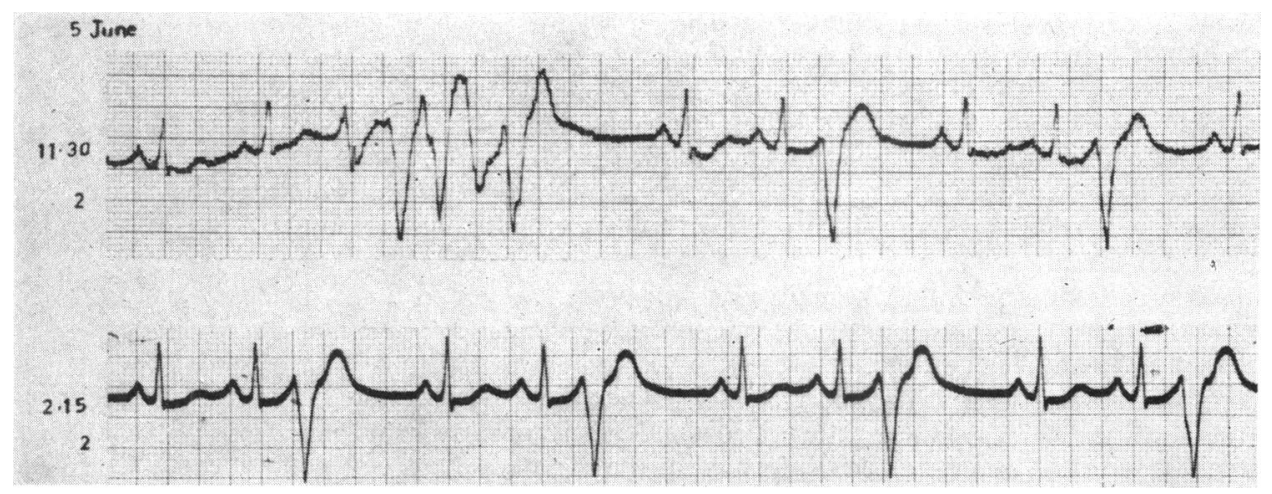

Fig. 3.-Case 1. Electrocardiogram between Stokes-Adams attacks during June 5, 1960. 


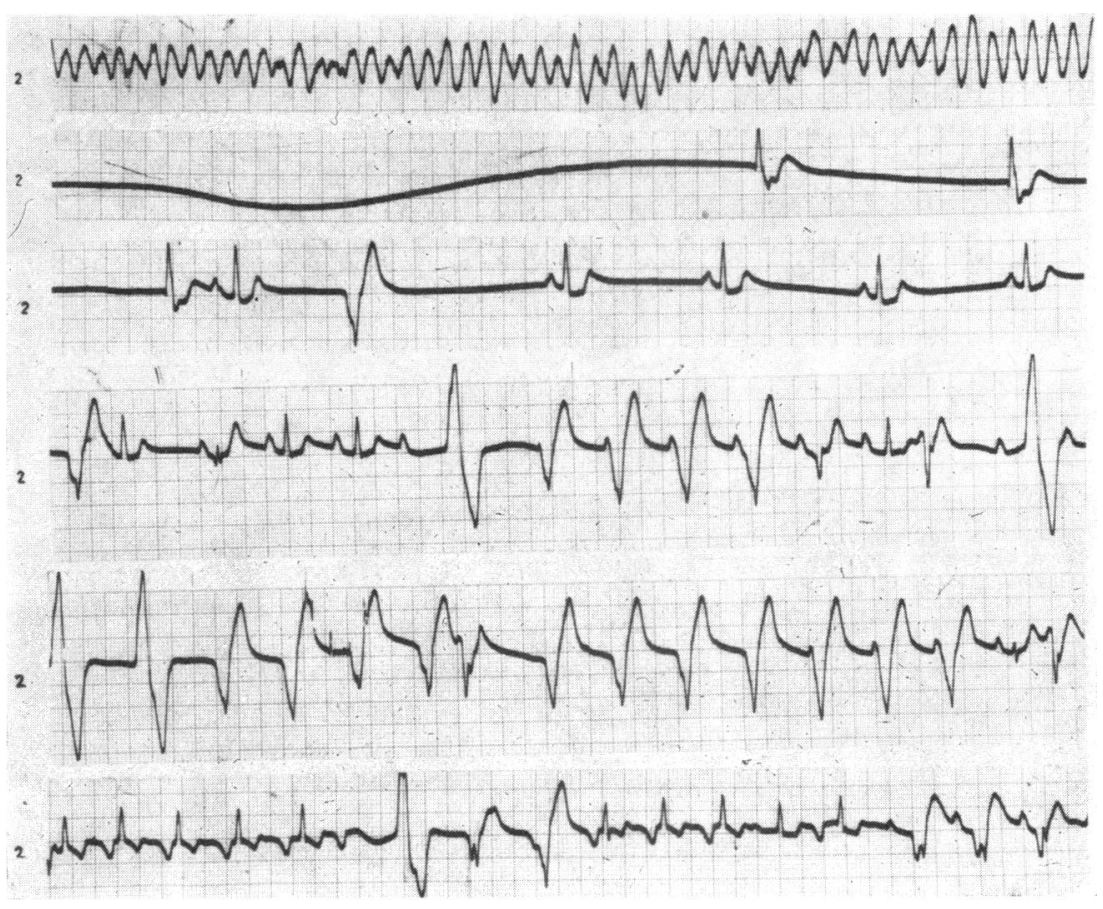

FIG. 4.-Case 1. Electrocardiogram lead II during a Stokes-Adams attack, showing ventricular fibrillation, followed by complete cardiac arrest, nodal escape, and multifocal ectopic beats.

external cardiac massage nor external defibrillation were available in this hospital.) In the final episode, after $2 \frac{1}{2}$ minutes the house physician performed bimanual internal cardiac massage for approximately one minute, after which cardiac action was restored spontaneously. During the next 24 hours, $13 \mathrm{~g}$. of procaine amide were given intravenously, and Omnopon and sodium phenobarbitone were also given. Sedation had been overlooked previously. It was found that ventricular ectopics could be controlled with this régime and no further attacks occurred.

Serum glutamic oxalacetic transaminase activity remained normal. The electrocardiogram did not show changes of infarction. He had no ischæmic cardiac pain, and the underlying basis of the attacks was not discovered.

The patient was discharged from hospital 20 days after the last attack and has remained well and at work for the past $3 \frac{1}{2}$ years. He takes quinidine $200 \mathrm{mg}$. and procaine amide $250 \mathrm{mg}$. each four times daily. Only rarely does he notice palpitation.

Case 2. A 76-year-old woman, with a history of angina pectoris for several years and an episode of known myocardial infarction two years previously, woke at $4.00 \mathrm{a} . \mathrm{m}$. with anterior chest pain extending into the left arm. At $5.00 \mathrm{a} . \mathrm{m}$. she felt faint and suddenly became unconscious. Her husband, a retired physician, noted that her pulse and respirations were temporarily absent. On regaining consciousness the pulse began at a rate of 40 a minute, then returned to 80 a minute. She vomited. At 7.00 a.m. a similar attack occurred.

Examination at 9.00 a.m. when the pain was still present revealed a pulse rate of 80 a minute, blood pressure of $120 / 80 \mathrm{~mm}$. $\mathrm{Hg}$, and the venous pressure slightly raised. The heart sounds were faint but a presystolic triple rhythm was audible.

The electrocardiogram (Fig. 5) revealed a P-R interval of 0.24 sec. and intermittent Wenckebach type atrio-ventricular block. Before taking the præcordial leads it was apparent that a fresh posterior myocardial infarction was present. The patient was informed of the diagnosis before recording lead V1. She said she was distressed to have her fears confirmed. Lead V1 showed ventricular ectopic beats. She was told that she would have to be admitted to hospital. Lead V2, taken immediately, revealed ventricular fibrillation. 


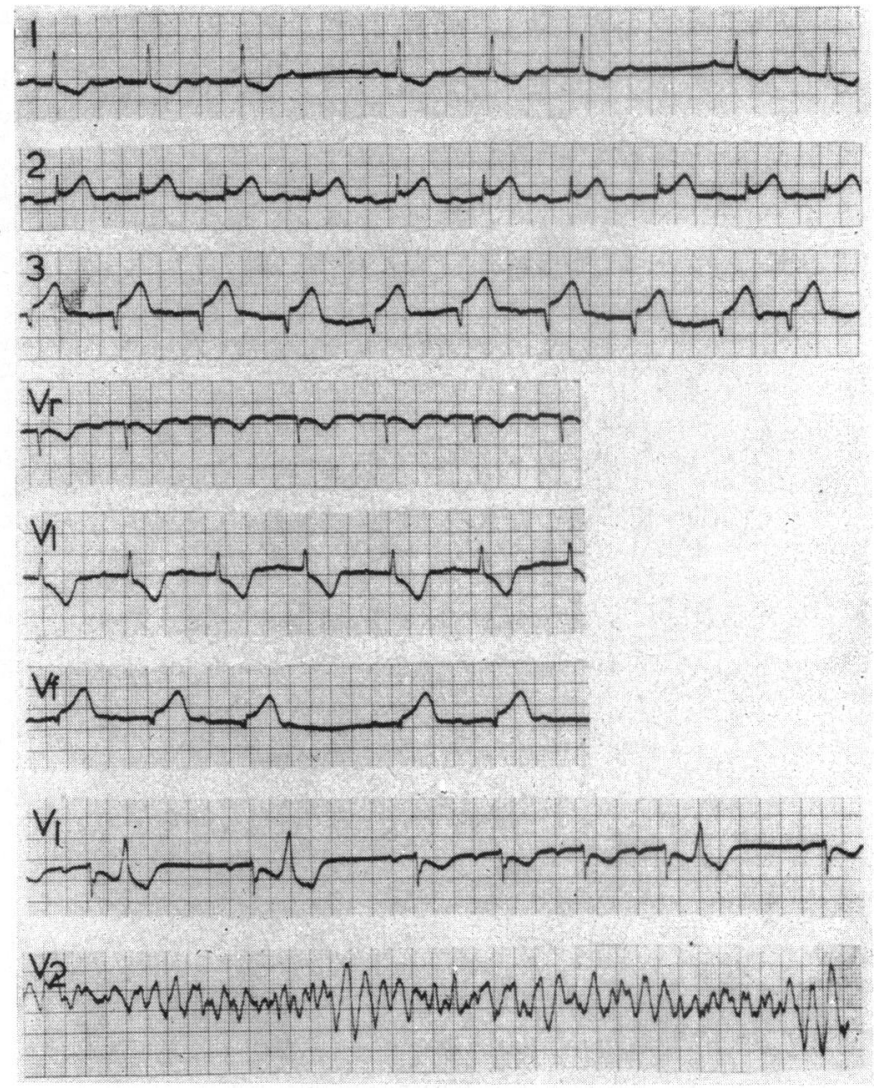

Frg. 5.-Case 2. Electrocardiogram demonstrating recent posterior myocardial infarction and low grade atrio-ventricular block. Ventricular ectopics appear in lead V1; ventricular fibrillation in lead V2.

Half way through the recorded strip she said "I think I am going to faint" and immediately became unconscious.

The time was noted, the electrocardiograph turned to lead III, the mattress found to be firm, and external cardiac massage instituted. The patient's husband adjusted the chin to assure an airway. As her colour remained good, mouth-to-mouth respiration was not undertaken. The pupils remained small. Each minute a short strip of electrocardiogram was recorded (Fig. 6). Ventricular fibrillation persisted for seven minutes. This was then followed by complete atrio-ventricular block for four minutes, after which sinus rhythm reappeared and the patient regained consciousness. She apologized for momentarily going to sleep.

She was taken to hospital by ambulance, connected to an electrocardiograph monitor and given intravenous sodium amylobarbitone to produce sleep. This resulted in the cessation of ectopic beats. Sleep was maintained for two days with intramuscular sodium phenobarbitone. The patient was mentally confused for the next two days. She sat out of bed on the fifth day and was walking on the twelfth day.

Serum glutamic oxalacetic transaminase activity on the second day was 310 units, confirming the large size of the infarct.

After leaving hospital amylobarbitone $50 \mathrm{mg}$. and quinidine sulphate $200 \mathrm{mg}$. were given three times daily. When the amylobarbitone was temporarily stopped ventricular ectopics recurred. Apart from this, and occasional anginal pain, the patient remained well for 13 months until she died suddenly one hour after the onset of a severe continuing anterior chest pain. 
FIG. 6.-Case 2. Electrocardiogram during Stokes-Adams attack (lead III). Ventricular fibrillation is present during the first seven minutes, followed by complete atrio-ventricular block, then sinus rhythm.

\section{DisCUSSION}

Precipitation and Control of Attacks. The production of cardiac arrhythmia by anxiety has been reviewed by Wolf (1958). A relation between psychological stress and sudden death in patients with myocardial infarction was suggested by Järvinen (1955). The occurrence of attacks of paroxysmal ventricular tachycardia and ventricular fibrillation, following emotional stimuli in a child, has been reported by Horan and Venables (1962). Hoffmeister, Regelson, and Rubin (1958) showed that non-specific sedation reduced the incidence of ventricular fibrillation that followed acute occlusion of the anterior descending ramus of the left coronary artery of dogs. In both cases reported here, anxiety appeared to trigger attacks, while heavy sedation prevented them and controlled ventricular ectopic beats.

The first patient suffered from 15 Stokes-Adams attacks during a 24-hour period. Most of the attacks were monitored on an oscilloscope and in each case paroxysmal ventricular fibrillation was observed or recorded as in Fig. 4. Despite large doses of procaine amide the attacks recurred with increasing frequency. Between attacks there were frequent ventricular ectopics (Fig. 3). The patient received no sedation and was anxious until thoracotomy, following which he was sedated. No attacks occurred thereafter. It was clear in retrospect that the attacks occurred during anxietyproducing situations.

The possible significance of anxiety in the precipitation of attacks in the first patient was not recognized at the time. In the ensuing 18 months, before the second case presented, two patients 
were seen with frequent Stokes-Adams attacks, due to ventricular fibrillation, in association with complete heart block; in them it was noted that attacks and ectopic beats could be provoked by verbal, visual, or tactile stimuli (even by feeling the pulse or entering the patient's room); the attacks could be prevented completely by heavy sedation. This experience affected management of the second patient.

The second patient, well aware of the significance of her attack of præcordial pain, had two Stokes-Adams attacks before that recorded in Fig. 5 and 6 . When told the diagnosis, ventricular ectopic beats appeared; when informed that she would require admission to hospital, ventricular fibrillation ensued. In hospital, ectopic beats ceased following intravenous amytal to induce unconsciousness.

The Place of Cardiac Massage. The first patient's illness occurred before the efficacy of external cardiac massage was recognized and at a time before an external defibrillator was available. This necessitated timing the duration of each attack by stop watch, and the unquestioned opening of the chest after $2 \frac{1}{2}$ minutes in the 15 th attack. It is probable that reversion to sinus rhythm in this case was spontaneous and not related to the one minute of internal massage.

The use of external massage alone was sufficient to achieve survival of the second patient. The successful result supports the view that external massage should be performed on patients with circulatory arrest due to ventricular fibrillation even when a defibrillator is not available (Estes, 1962). This has also been the experience of Wetherill and Nixon (1962), Semple and Dall (1962), Harden, Mackenzie, and Ledingham (1963), and Ben Hur, Rachmilewicz, and Eliakim (1963), each having reported one patient with myocardial infarction in whom sinus rhythm was restored, following cardiac massage, without defibrillation. Priest (1949) and Choquette et al. (1956) each reported one patient with ventricular fibrillation following acute myocardial infarction, reverting to sinus rhythm without cardiac massage.

In the second patient, adequate oxygenation was possible during seven minutes of external cardiac massage, without aid to respiration beyond maintaining an unobstructed airway. This was also found possible in a patient reported by Colmers and Gammill (1963).

Incidence. Electrocardiographic monitoring of patients under special circumstances shows that the incidence of short paroxysms of ventricular fibrillation in patients with sinus rhythm may be greater than has been believed. Sones and Shirey (1962) refer to 12 cases of ventricular fibrillation during coronary arteriography, one of which reverted spontaneously after 20 seconds. Schwartz and Schwartz (1963) refer to 3 patients with transient ventricular fibrillation in a group of 30 patients who were subject to Stokes-Adams attacks during sinus rhythm and transient heart block. Julian, Valentine, and Miller (1964), reporting the results of continuous electrocardiographic monitoring of 100 patients with acute myocardial infarction, found ventricular fibrillation to be transient in 1 of the 10 patients in whom it occurred.

\section{SUMMARY}

Two patients are reported in whom attacks of paroxysmal ventricular fibrillation occurred from sinus rhythm and who recovered without electrical defibrillation. In one the underlying pathology was obscure; in the other it was myocardial infarction.

The apparent precipitating cause of the attacks was acute anxiety. Heavy sedation was considered responsible for preventing further attacks.

Cardiac massage was sufficient to permit survival in both cases.

It is suggested that paroxysms of ventricular fibrillation of short duration may be more frequent than is supposed.

I wish to thank Dr. K. Tung, who performed internal cardiac massage, and Mr. W. Kune and Mr. I. McConchie, who managed the thoracotomy in the first patient. Survival of both patients was made possible through the intensive care maintained by resident medical and nursing staff of the Royal Melbourne Hospital. 


\section{REFERENCES}

Ben Hur, N., Rachmilewicz, E. A., and Eliakim, M. (1963). Repeated rususcitation in a patient with myocardial infarction. Amer. J. Cardiol., 11, 808.

Choquette, G., Wasserman, F., Lisker, S., and Bellet, S. (1956). Spontaneous reversion of ventricular fibrillation to normal sinus rhythm in a case of acute myocardial infarction. Amer. Heart J., 51, 455.

Colmers, R. A., and Gammill, J. F. (1963). Successful resuscitation by closed chest cardiac compression and repeated defibrillation in acute myocardial infarction. Amer. J. Cardiol., 11, 814.

Estes, E. H. (1962). The emergency management of acute cardiac arrhythmia. Med. Clin. N. Amer., 46, 331.

Gilchrist, A. R. (1958). Clinical aspects of high-grade heart block. Scot. med. J., 3, 53.

Harden, K., Mackenzie, I. L., and Ledingham, I. McA. (1963). Spontaneous reversion of ventricular fibrillation. Lancet, 2, 1140.

Hoffmeister, F. S., Regelson, W., and Rubin, H. (1958). Effect of central depression on survival following acute coronary occlusion. Surg. Forum, $9,242$.

Horan, M., and Venables, A. W. (1962). Paroxysmal tachycardia with episodic unconsciousness. Arch. Dis. Childh., 37, 82.

Järvinen, K. A. J. (1955). Can ward rounds be a danger to patients with myocardial infarction? Brit. med. J., $1,318$.

Jude, J. R., Kouwenhoven, W. B., and Knickerbocker, G. G. (1961). Cardiac arrest: report of application of external cardiac massage on 118 patients. J. Amer. med. Ass., 178, 1063.

Julian, D. G., Valentine, P. A., and Miller, G. G. (1964). Disturbances of rate, rhythm, and conduction in acute myocardial infarction. Amer. J. Med. In the press.

Kouwenhoven, W. B., Jude, J. R., and Knickerbocker, G. G. (1960). Closed-chest cardiac massage. J. Amer. med. Ass., 173, 1064

Parkinson, J., Papp, C., and Evans, W. (1941). The electrocardiogram of the Stokes-Adams attack. Brit. Heart J., $3,171$.

Portal, R. W., Davies, J. G., Leatham, A., and Siddons, A. H. M. (1962). Artificial pacing for heart block. Lancet, 2, 1369 .

Priest, W. M. (1949). Ventricular fibrillation recorded ten hours before death from myocardial infarction. Lancet, $2,699$.

Schwartz, L. S., and Schwartz, S. P. (1963). The Adams-Stokes syndrome during normal sinus rhythm and transient heart block. IV. The effects of altered posture. Amer. J. Cardiol., 12, 505.

Semple, T., and Dall, J. L. C. (1962). External cardiac massage. Lancet, 1, 324.

Sones, F. M., Jr., and Shirey, E. K. (1962). Cine coronary arteriography. Mod. Conc. cardiovasc. Dis., 31, 735.

Wetherill, J. H., and Nixon, P. G. F. (1962). Spontaneous cessation of ventricular fibrillation during external cardiac massage. Lancet, 1,993.

Wolf, S. (1958). Cardiovascular reactions to symbolic stimuli. Circulation, 18, 287.

Zoll, P. M., Linenthal, A. J., Gibson, W., Paul, M. H., and Norman, L. R. (1956). Termination of ventricular fibrillation in man by externally applied electric countershock. New Engl. J. Med., 254, 727. 